\title{
Comportamiento diacrónico del Congreso en CHILE: ¿CREcimiento O ESTANCAMIENTO DE SU INFLUENCIA?
}

\author{
Cross-Time Behaviour of the Chilean Congress: Growth or Stagnation \\ of its Influence?
}

\section{GIANCARLO VISCONTI*}

Pontificia Universidad Católica, Chile

\begin{abstract}
RESUMEN
Esta investigación examina el comportamiento diacrónico del Legislativo chileno desde 1990 hasta el 2009, estudiando las variables que influyen en sus niveles de productividad. Se observa que éstos no son homogéneos a través de los años, planteándose dos explicaciones principales: la primera es la existencia de ciertos ciclos políticos -el primer año de gobierno y las elecciones parlamentarias-y la segunda es un proceso institucional de largo plazo entendido como la acumulación de experiencia democrática del Congreso. Estas variables explicativas son testeadas a través de un modelo de regresión logística, que permite concluir que bajo estas condiciones y procesos institucionales los congresistas presentan una mayor productividad legislativa, funcionando como un cuerpo coherente y coordinado.
\end{abstract}

Palabras clave: Legislativo, Chile, productividad, mociones, coordinación parlamentaria.

\begin{abstract}
This research examines the cross-time behaviour of Chilean legislature from 1990 to 2009, studying the variables that influence their levels of productivity. It is noted that these are not homogeneous over the years, considering two main explanations: the first is the existence of certain political cycles -the first year of government and parliamentary elections-and the second is a long-term institutional process understood as the accumulation of democratic experience in Congress. These explanatory variables are tested through a logistic regression model, which suggests that under these conditions and institutional processes exist a greater legislative productivity in Congress, functioning as a coherent and coordinated body.
\end{abstract}

Key words: Legislative, Chile, productivity, Congress bills, parliamentary coordination.

* El autor agradece especialmente a David Altman, Sergio Toro, Valeria Palanza y a los dos referís anónimos por las valiosísimas observaciones y sugerencias a esta investigación. Además, a María Jimena Cosso y Micaela Lobos por sus comentarios en los aspectos formales del artículo. Los errores u omisiones son de exclusiva responsabilidad del autor. 


\section{INTRODUCCIÓN}

En 1990 se reinstaura la democracia en Chile tras 17 años de autoritarismo, a través de elecciones libres y justas asume Patricio Aylwin como presidente de la república y el Congreso Nacional recupera sus funciones. Transcurridos cuatro períodos presidenciales y cinco parlamentarios se vuelve interesante analizar la relación entre el Poder Ejecutivo y el Legislativo a través de nuevos enfoques y variables explicativas. La hipótesis de este artículo es que los congresistas aumentan sus niveles de productividad legislativa durante el primer año de gobierno y la época de elecciones parlamentarias. Además el Congreso ha logrado acumular experiencia y desarrollar habilidades a lo largo de los años, esto le permite ser un órgano más eficiente y coordinado. Todo esto acontece en el contexto de un sistema hiperpresidencialista, donde el presidente cuenta con suficientes privilegios constitucionales para ser el actor principal de la relación entre ambos poderes (Payne et al., 2006; Siavelis, 2000).

Esta investigación marca diferencias con otros estudios legislativos en dos aspectos principales. En primer lugar, se analizan las materias de ley aprobadas provenientes de ambos poderes evitando una visión unidireccional desde el Ejecutivo hacia el Legislativo. En segundo lugar el estudio no se concentra solo en variables tradicionales como el contingente del presidente, la disciplina partidaria o los poderes presidenciales para explicar la conducta del Parlamento. Este artículo utiliza nuevas aproximaciones para el caso chileno, las cuales se centran en dos aspectos principales: los ciclos políticos y los procesos institucionales de largo plazo. Dentro de los ciclos políticos se estudian los efectos del primer año de gobierno y los años de elecciones parlamentarias en el comportamiento legislativo. Como procesos institucionales de largo plazo entendemos la progresiva acumulación de experiencia democrática del Congreso, que le ha permitido modificar su conducta gradualmente.

Se asume que los miembros del Congreso son actores racionales motivados por dos objetivos: la producción de políticas y la búsqueda de la reelección (Bond et al., 2002). En función de estas dos características los congresistas no organizan su comportamiento bajo la lógica de la dispersión o la confrontación ideológica irreconciliable, sino que funcionan como un cuerpo legislativo coherente, en donde las diferencias de bancadas o partidos -en ciertas ocasiones- se postergan a un segundo plano buscado el desarrollo como institución legislativa.

Esto se logra aumentando la productividad, es decir, aprobando más leyes provenientes del Congreso y que éstas tengan mayor relevancia política. De esta manera los parlamentarios son capaces de posicionarse como actores relevantes y enfrentar la reelección como políticos productivos. Los principales objetivos de esta investigación son indagar si estas características se cumplen para el Congreso chileno, y estudiar cuáles son las circunstancias en donde los parlamentarios pueden adoptar un rol más protagónico frente al Ejecutivo en términos de producción de materias de ley.

En América Latina el Poder Legislativo ha sido observado tradicionalmente como un rubber stamp o un impedimento para el trabajo eficiente del Ejecutivo (Siavelis, 2002). 
Sin embargo, en Chile los legisladores no estructuran su conducta de forma pasiva u obstaculizadora, sino que adoptan una actitud proactiva intentando influir en el proceso de toma de decisiones políticas (BID, 2006). Independiente del partido, coalición o ideología que posean los parlamentarios todos tienen un objetivo en común: ser una institución más poderosa en términos productivos, en donde la agregación de intereses es una pieza clave para lograr el objetivo. Por lo tanto, las motivaciones distritales (como el credit claiming y constituency service) y las partidarias (el clásico choque oposición-oficialismo) logran conciliarse con las propiamente parlamentarias (desarrollo institucional a través del aumento de la productividad). Esta lógica institucional no se genera de forma natural solo con las motivaciones de carrera y de policy, sino que se deben dar dos condiciones estrictamente necesarias: la existencia de la reelección parlamentaria (y el éxito de los incumbents en las urnas) y el desarrollo de la coordinación intra e intercoalicional en los parlamentarios. La primera es fácilmente demostrable, ya que Chile posee la tasa de reelección más elevada de América Latina (BID, 2006), en cambio la segunda condición es más compleja de evidenciar, por ende, se le dedicará un apartado especial para su profundización.

El Congreso en Chile, a pesar de sus escasos poderes constitucionales, realiza un importante aporte tanto en la formación de la agenda como en la especificación y definición de alternativas de políticas (BID, 2006; Saiegh, 2010). Esta característica se ha ido desarrollando a través de los años, y este artículo demuestra que la productividad legislativa en los comienzos de la nueva democracia es estadísticamente inferior que veinte años después, a pesar de que la mayoría de las características del Congreso se mantuvieron constantes.

Esta investigación analiza todas las leyes aprobadas en el Congreso desde marzo de 1990 hasta febrero de 2010, ${ }^{1}$ éstas pueden tener su origen en el Ejecutivo (mensajes) o en el Legislativo (mociones). Por ende, para que el Parlamento sea capaz de posicionarse como un actor más relevante en términos de políticas debe aumentar el porcentaje de mociones aprobadas en relación al total de leyes aprobadas y que éstas tengan más peso o relevancia política. El análisis de mociones aprobadas puede basarse desde dos perspectivas diferentes, la primera es comparar las mociones aprobadas con las mociones presentadas y la segunda es comparar las mociones aprobadas con el total de leyes aprobadas. La primera perspectiva genera una visión unidireccional al desconocer qué sucede con los mensajes. Este estudio utiliza la segunda perspectiva para controlar lo que sucede en el Ejecutivo y ser capaz de establecer un análisis más amplio y no sesgado a solo uno de los poderes. Cuando comparamos mociones aprobadas con mociones presentadas nos remitimos solo a comprender lo que sucede en el Parlamento, siendo difícil establecer una relación con el comportamiento del Presidente, lo mismo ocurre cuando se analizan mensajes aprobados con mensajes enviados. Podría comentarse que lo óptimo sería comparar mociones presentadas con el total de leyes presentadas para un análisis más amplio, sin embargo esta investigación intenta estudiar la productividad legislativa. 
Por ende, las leyes deben estar aprobadas y no solo presentadas para considerar que el Congreso es más poderoso en términos productivos.

La aprobación de mociones depende también de los intereses partidarios o coalicionales. Sin embargo, la investigación observa diferencias significativas en las tasas de productividad legislativa a lo largo de los años. Por consiguiente, se da pie para plantear hipótesis alternativas a las partidarias o a las relacionadas al contingente legislativo del presidente. Esto no implica que los legisladores oficialistas busquen ir en contra del Ejecutivo, sino que intentan desarrollarse como institución aprobando más y mejores leyes propias. Ambas lógicas son completamente compatibles en democracias consolidadas.

El trabajo se divide en cinco partes sin incluir la introducción. Primero se analizan las características institucionales de la legislatura a nivel comparado, y se revisan los distintos estudios sobre el Congreso chileno y su relación con el Ejecutivo. En segundo lugar se profundiza en la coordinación parlamentaria, como variable explicativa del paulatino desarrollo institucional del Congreso. En tercer lugar se estudian los ciclos políticos que permiten una mayor productividad legislativa (primer año de gobierno y año de elecciones parlamentarias) y se analiza la importancia de la acumulación de experiencia democrática o los años de vida del Congreso. Como cuarto punto se presentan dos modelos de regresión y se interpretan sus resultados para finalizar con las conclusiones del estudio.

\section{EL CONGRESO CHILENO: PERSPECTIVA COMPARADA Y ESTADO DEL ARTE}

Al momento de estudiar cualquier legislatura, se debe tener como referencia al Congreso de Estados Unidos, probablemente la institución política más estudiada en el mundo (Jones et al., 2002). Algunas de sus características principales, en palabras de los mismos autores se enumeran a continuación: (1) sus miembros poseen una notable longevidad, (2) los legisladores tienden a especializarse en comités, (3) el Congreso juega un rol activo en el policymaking y (4) la legislatura cumple un rol importante en la fiscalización/ vigilancia sobre la administración pública.

Una de las investigaciones más trascendentales para el estudio del US Congress en particular y para los estudios legislativos en general es el trabajo de David Mayhew (1974), cuya tesis puede resumirse en que los miembros del Parlamento tienen el interés primario de ser reelectos. De esta manera, el comportamiento legislativo se estructura bajo la lógica de la ambición. Para poder cumplir con este objetivo los legisladores deben realizar una serie de actividades para asegurar la reelección, éstas son el advertising, el credit claiming y el position taking. El autor caracteriza este aspecto de manera muy clara en el siguiente ejemplo: Congressman Smith is unbeatable as long as he continues to do the things he is doing (Mayhew, 1974: 37). Por lo tanto, un congresista no solo debe querer ser reelecto sino que también debe trabajar en función de esa ambición.

Otro trabajo trascendental es el de Polsby (1968); el autor estudió la institucionalización del US Congress, planteando como características básicas del proceso: (1) La organización 
debe estar bien delimitada, diferenciada del ambiente. Sus miembros deben ser fácilmente identificados, siendo relativamente difícil convertirse en uno de ellos. En términos aplicados existe un bajo turnover de sus miembros, por ende, la existencia de una carrera parlamentaria es una de sus principales características. (2) La institución debe ser relativamente compleja, sus funciones deberían estar internamente separadas. En términos aplicados deben existir comisiones permanentes y profesionalizadas. (3) La organización tiende a un criterio universal y no particular. Con un proceso decision-making automático y discrecional. En términos prácticos la existencia de seniority en sus miembros.

En síntesis, el US Congress es una organización política profundamente institucionalizada y con gran relevancia en el policymaking, en donde sus actores se comportan en función de la teoría de la ambición.

Cuando deseamos estudiar la productividad legislativa, es necesario recordar el clásico e influyente trabajo de Mayhew (1991). El autor examina la relación entre productividad y gobierno unificado, encontrando que éstos no se correlacionan: divided we govern. En general, la literatura que se ha preocupado de la productividad legislativa tiene dos características principales: corresponde a American Politics y sus variables explicativas han radicado en los partidos políticos y los contingentes legislativos del presidente (Howell et al., 2000). Sin embargo, existen algunas excepciones, el trabajo de Alemán y Calvo (forthcoming) intenta medir el peso legislativo que poseen el Congreso y el Ejecutivo en sistemas presidenciales (non-US). Los autores plantean como argumento central que éste depende de "variables políticas contextuales", como por ejemplo los ciclos políticos. El peso relativo de cada institución es entendido como una variable latente, sensible a los cambios políticos contextuales. Esto implica que los poderes presidenciales no sean la única forma de medir y entender los procesos de lawmaking para el Congreso y el Ejecutivo. Bajo esta misma línea de investigación, Calvo (2007) combina las variables institucionales (decretos, vetos, indicaciones, etc.) con las contextuales (aprobación presidencial), para explicar el éxito legislativo del presidente en congresos altamente disciplinados y cartelizados. El principal hallazgo del autor es que la disciplina partidaria y los modelos espaciales de voto pueden fallar a la hora de predecir el éxito de los proyectos de ley. Entender la productividad como una variable latente, sensible a factores que trascienden los aspectos institucionales, es un elemento central para comprender de mejor manera la interacción entre ambos poderes. Este punto ha sido descuidado por la literatura a la hora de entender el comportamiento de la legislatura chilena.

Profundizando en las legislaturas en América Latina, la literatura concuerda en que tienen un papel menos activo que el Congreso de Estados Unidos, éstas toman generalmente un rol reactivo (Morgenstern, 2002). No obstante, existen importantes varianzas y diferencias entre los congresos latinoamericanos (Saiegh, 2010). Éstas se explican principalmente por las diferencias institucionales entre los países: la reelección, los alineamientos partidarios, los poderes constitucionales y el sistema electoral (Morgenstern, 2002).

En términos comparados, el Congreso chileno se encuentra bastante bien posicionado, superando el promedio regional (Altman y Chasquetti, 2005). Chile posee la tasa de 
reelección más alta de América Latina y lidera el índice de capacidad parlamentaria junto a Brasil, Colombia y Uruguay (BID, 2006). Mientras que Saiegh (2010), a través de un análisis de escalamiento multidimensional confirma los resultados anteriores para la legislatura chilena. Ambos estudios muestran que a pesar de los altos poderes constitucionales del presidente, el Congreso es capaz de tomar un rol activo en la arena política. El Congreso chileno cumple, o está en vías de cumplir, las características que Polsby (1968) describió para la institucionalización: existe una alto nivel de reelección (Morgenstern, 2002; Altman y Chasquetti, 2005), las comisiones permiten la profesionalización del trabajo legislativo (Carey, 2002), los legisladores poseen static ambition desarrollando la carrera parlamentaria (Morgenstern, 2002) y la legislatura comienza a tomar cada vez más relevancia en el proceso de decision-making (Saiegh, 2010).

Bajo estas condiciones, es posible afirmar que la legislatura chilena busca su desarrollo y potenciación como institución. En palabras de Saiegh (2010: 23): la institucionalización de cualquier legislatura se inicia con el reconocimiento, por parte de sus miembros, de que deben dedicar parte de su tiempo y esfuerzo a construir un cuerpo colectivo más fuerte, por lo tanto, es necesario concentrarse en los incentivos que deben tener los congresistas para invertir en la legislatura. Este proceso de desarrollo e institucionalización se debiera evidenciar de manera empírica en un aumento de la productividad legislativa, en términos de cantidad y de calidad de leyes propias aprobadas. Sin embargo, la importancia de un Congreso no puede medirse solo en términos de productividad, también en capacidades reactivas como bloquear legislaciones no favorables, presionando al presidente o corrigiendo sus proyectos (Morgenstern, 2002). No obstante esta apreciación, la presente investigación se focaliza en las capacidades proactivas del Congreso, es decir, en la productividad como proxy de desarrollo legislativo a nivel institucional. Para esto es necesario que la estabilidad sea una de las características esenciales de la legislatura local, entendiendo que cuando aumenta la estabilidad de los miembros, el Parlamento desarrolla reglas y aumenta la complejidad institucional (Polsby, 1968).

Las características institucionales del Congreso en Chile difieren de otros países latinoamericanos. Por ejemplo, el Congreso argentino juega un rol limitado en la producción de políticas públicas y es relativamente ineficiente en el chequeo del Poder Ejecutivo. La reelección de los legisladores está en manos de los jefes de partido provincial o gobernador provincial y no en la de los votantes. Estas reglas limitan la habilidad de los legisladores para desarrollar una carrera legislativa, reduce sus incentivos para especializarse y disminuye el desarrollo de una institución legislativa fuerte. La evidencia empírica muestra una corta duración de la carrera legislativa (Jones et al., 2002). Mientras que en Brasil, el Congreso se utiliza como plataforma política para acceder a otros cargos afectando las carreras legislativas y la profesionalización de la legislatura (Samuels, 2000).

Luego de evaluar al Congreso chileno en perspectiva comparada es necesario profundizar en sus características propias y lo que ha dicho la literatura sobre éstas. En primer término, es preciso situarse en los comienzos de una rica construcción teórica que se dio dentro de la Política Comparada, luego que Linz (1978) planteara que los presidencialismos 
sufrían problemas estructurales que afectaban la estabilidad democrática. Entre las consecuencias que este sistema político podía causar se encontraban algunas que impactaban directamente la relación entre ambos poderes del Estado: los bajos incentivos para formar coaliciones, las altas posibilidades de tener gobiernos minoritarios y la ineficacia legislativa, todas estas pudiendo derivar en un deadlock o bloqueo entre ambos poderes (Chasquetti, 2008). Esta visión marca la literatura sobre la relación entre el Ejecutivo y el Legislativo.

Para el caso chileno, se enmarcó en sus inicios en recordar constantemente la característica de hiperpresidencialismo del sistema político, centrando el análisis en una perspectiva unidireccional: desde el presidente hacia el Parlamento, relación que se encontraba cimentada en los poderes proactivos y reactivos del gobernante. Siavelis (2000) destaca las debilidades del Legislativo frente al Ejecutivo, en donde el primero carece de ciertas prerrogativas constitucionales como las iniciativas exclusivas y las urgencias, cumpliendo un rol subordinado dentro de la estructura política chilena. Las amplias facultades con que goza el presidente limitan fuertemente las capacidades de los parlamentarios impidiendo que éstos puedan ser un verdadero contrapeso a las iniciativas ejecutivas.

Luego de más de una década del retorno a la democracia comienzan a relativizarse muy sutilmente estas condiciones. Siavelis (2002) replantea su tesis anterior al observar que efectivamente los poderes presidenciales son exagerados, pero la figura del presidente se ha destacado por la moderación, principalmente para permitir un efectivo coalitionbuilding y de esta manera controlar la agenda y la producción legislativa. A pesar de que la tesis de Peter Siavelis modera los poderes presidenciales sigue manteniendo el enfoque que subordina la labor parlamentaria a los intereses del Ejecutivo. Carey (2002) destaca al Congreso chileno como uno de los más eficientes en la región en términos de influencia sobre las políticas gubernamentales. El autor plantea un aspecto fundamental para comenzar a relativizar las tesis de subordinación legislativa: la reelección parlamentaria como un incentivo institucional para la profesionalización del trabajo legislativo, permitiendo así tener funcionarios más capacitados y competentes en el policymaking.

Existe una segunda vertiente académica, la que se inmiscuye dentro del Legislativo estudiando aspectos esenciales como la disciplina partidaria y el posicionamiento ideológico (Carey, 2002; Toro, 2007; Londregan, 2000; Alemán y Saiegh, 2007). Los resultados arrojan que los parlamentarios presentan altos niveles de disciplina tanto partidaria como coalicional, destacando el caso de la Concertación, ${ }^{2}$ la cual ha estructurado su comportamiento, en la mayoría de las votaciones, como un macropartido sin existir divergencias importantes dentro de sus filas. El hecho de ser gobierno genera fuertes incentivos que fomentan la unidad parlamentaria, siendo ésta la principal explicación para que la Alianza por Chile $^{3}$ presente menores niveles de disciplina que los parlamentarios oficialistas. Los miembros individuales del Congreso no tienden

La Concertación se encuentra compuesta por el Partido Socialista (PS) , el Partido por la Democracia (PPD), el Partido Radical Social Demócrata (PRSD) y la Democracia Cristiana (DC).

3 La Alianza por Chile está compuesta por Renovación Nacional (RN) y la Unión Demócrata Independiente (UDI). 
a actuar de forma unitaria ni por intereses meramente distritales o localista, el factor con mayor significancia para explicar el voto parlamentario es la pertenencia a una coalición (Carey, 2002).

Las coaliciones han sido un tema bastante estudiado dentro del Congreso, existiendo un consenso dentro de la literatura para explicar su formación y mantenimiento desde 1990. La variable explicativa recae sobre los incentivos generados por el sistema electoral, que al poseer una magnitud igual a dos permite un mapeo bipolar de los parlamentarios dentro del Congreso, con la existencia de dos grupos políticos estables, relativamente moderados y competitivos (Alemán y Saiegh, 2007). El Sistema Binominal ha permitido que las fuerzas partidarias dentro del Congreso se encuentren prácticamente inalteradas desde 1990, ya que la lógica del sistema permite que en la mayoría de los distritos sea electo un parlamentario de cada coalición. Esta lógica de funcionamiento influye en los altos niveles de disciplina partidaria, puesto que la verdadera elección no se juega en el distrito sino que en el proceso de negociación para formar parte de la lista parlamentaria. La selección de los candidatos que competirán en cada lista se encuentra tremendamente concentrada en las cúpulas partidarias y centralizada en la capital (Altman, 2008). Un congresista que no cumple con las órdenes de su partido a la hora de votar puede ver en peligro su repostulación al no ser considerado dentro de la lista, teniendo en cuenta que lograr romper el Sistema Binominal presentándose fuera de cualquier pacto es extremadamente complejo. Esto explica que los titulares, en la mayoría de los casos, sean denominados para el cargo salvo en el caso de extrema indisciplina del candidato (Siavelis, 2005).

Las variables pertenecientes al calendario electoral y a la aprobación presidencial fueron examinadas por Alemán y Navia (2009) como variable independiente del éxito del Ejecutivo en el Congreso, sus resultados mostraron que el primer año de gobierno o honeymoon es estadísticamente significativo en la aprobación de leyes enviadas desde el Ejecutivo (mensajes presidenciales) y que la popularidad del presidente no afecta este mismo punto. Sin embargo, es necesario realizar dos observaciones puntuales en su apreciación del trabajo legislativo. La primera, es que el éxito de las propuestas gubernamentales en el Legislativo no contempla el número de leyes que se dejaron de enviar debido a una posible decepción en el Parlamento. La aprobación de mensajes pudo mantenerse incluso cuando el presidente no era muy apoyado por la ciudadanía, pero probablemente su escritorio debió verse reducido en espacio producto de las leyes que nunca fueron enviadas para evitar un fracaso. Este ejercicio ex ante que realiza el gobierno (Boeninger, 2007) es prácticamente imposible de medir por el investigador. Y la segunda, es que el análisis se sitúa desde el Ejecutivo hacia el Legislativo, lo cual produce ciertas limitaciones ya que se desconoce lo que acontece dentro del Congreso. La tasa de aprobación de mensajes pudo mantenerse constante, pero la de mociones elevarse significativamente en los ciclos políticos estudiados.

Para evitar estos inconvenientes metodológicos esta investigación analiza todas las leyes aprobadas diferenciándolas entre mociones y mensajes. Así es posible ver cómo cambia la producción legislativa controlando por la producción presidencial. 


\section{LA COORDINACIÓN PARLAMENTARIA}

El aumento de la coordinación de los funcionarios del Congreso, tanto a nivel intra como intercoalicional, es la explicación teórica para la siguiente afirmación: todos los parlamentarios poseen un interés en común, ser una institución más poderosa en términos productivos. Esta logra evidenciarse en una serie de instituciones e instancias en donde los congresistas han presentado un alto nivel de cooperación, coordinación y apoyo, trascendiendo incluso las diferencias coalicionales en ciertos momentos. Estas instituciones e instancias son presentadas a continuación y permiten confirmar la idea de un Congreso que busca potenciarse como institución.

La Teoría del Leviatán Legislativo (Cox y McCubbins, 1993) -aplicado para el caso de EE.UU.- permitió revalorizar el rol de los partidos políticos dentro de la legislatura, al plantear que los congresistas no actúan como entes dispersos, caóticos o impredecibles, sino que la organización partidaria es capaz de agregar los intereses particulares, distritales y locales para solucionar los dilemas de acción colectiva. En el caso chileno, los partidos también juegan un rol importante dentro del Congreso, ya que determinan quiénes conforman las mesas directivas a través de negociaciones, reparten las comisiones (siendo esto un interesante juego de zanahoria y garrote), son protagónicos en la selección de candidatos y permiten que un parlamentario pueda ir en busca de la reelección o no. Por ende, juegan un rol vital en la coordinación parlamentaria, permitiendo que el Legislativo actúe como un cuerpo coherente y ordenado, y que no prime una lógica individualista atomizando el comportamiento de los legisladores.

La reelección ha significado probablemente uno de los mayores incentivos para la profesionalización de la labor parlamentaria. Cuando el juego se repite, los actores son capaces de actuar de forma coordinada debido a un mayor manejo de la información (North, 1993). Los incumbents -en gran parte de los casos- logran retener el escaño (Carey, 2002), permitiendo que el Congreso esté conformado en parte importante por funcionarios de experiencia y conocimiento de los procesos legislativos. La conducta legislativa puede explicarse por el incentivo de ser reelecto (Mayhew, 1974) complementado con el interés de ser un actor más relevante en el proceso de producción de políticas y no solo un rubber stamp o un instrumento decorativo del sistema político. Un congresista con años de experiencia en la profesión es capaz de solucionar de forma más eficiente los dilemas de acción colectiva, conoce los procesos internos en el Congreso y los juegos de poder con el Ejecutivo. Otro factor en consideración es que en Chile la carrera legislativa no tiende a ser una plataforma para cargos de mayor relevancia fuera de la legislatura (Carey, 2002), no es común que un diputado abandone la vida política después de ejercer su primer período y normalmente la plataforma se da dentro del mismo Parlamento desde la Cámara Baja hacia la Alta.

Las comisiones también han permitido aumentar la capacidad legislativa (Carey, 2002) en términos de experiencia y coordinación. Debido a que son una instancia de profundización de las materias de ley por áreas temáticas en donde los congresistas trabajan con temas ad hoc a sus conocimientos, además que reciben visitas de expertos o miembros del 
Ejecutivo permitiendo un interesante intercambio de ideas. No es antojadizo que algunos autores planteen que las comisiones son el lugar en donde los legisladores entregan sus verdaderas opiniones (Londregan, 2000) y luego, en la votación en sala, tiendan a comportarse como bloques. La lógica de la zanahoria y el garrote también es aplicada en la composición de comisiones, ya que algunas son más importantes que otras. Por ejemplo, la de hacienda es la que reúne las mayores atribuciones sobre las leyes, por ende, el pertenecer a ella es un premio y el dejar de pertenecer un castigo. ${ }^{4}$

Otro aspecto que fomenta la coordinación son las mesas directivas y los procesos de negociación para su composición. Entre sus funciones se encuentran: manejar la comunicación entre ambas Cámaras, con el Ejecutivo y con la opinión publica, además de poseer cierto control sobre la agenda y las comisiones (Carey, 2002). Por lo tanto, los cargos directivos poseen un cierto nivel de relevancia para ser utilizado como moneda de cambio o incentivo de coordinación, entendiendo que la conformación de la mesa se logra después de procesos de negociación.

La fuerza de los partidos sobre sus parlamentarios puede revelarse también en dos circunstancias muy bien descritas por Toro (2007: 35); la primera correspondiente a los partidos oficialistas ${ }^{5}$ es conocida como reunión de los lunes en donde los jefes de partido y bancada de las instituciones oficialistas tienen como objetivo acordar iniciativas que tengan los respaldos necesarios para su discusión dentro del Congreso; y la segunda en el partido de oposición UDI, en donde el gobierno busca a personalidades específicas para negociar ciertas materias, un acuerdo con Pablo Longueira en temas políticos o con Marcelo Forni en cuestiones institucionales, aseguraba el concurso de todos sus diputados. Ambos ejemplos del mismo autor nos muestran que los partidos políticos tanto pertenecientes a la coalición gobernante $u$ opuestos a ella son capaces de influenciar fuertemente la labor de sus parlamentarios.

Una instancia que se da entre los parlamentarios, y no ha sido muy estudiada, son los pareos. De acuerdo a la definición oficial el sistema de pareos se aplica entre parlamentarios de partidos opuestos y se hace efectivo en caso de ausencia de una de las dos personas. Los parlamentarios pueden parearse entre sí, por escrito, obligándose a no participar en ninguna votación o elección durante el plazo que convengan, o en aquellas votaciones o elecciones específicas que indiquen. ${ }^{6}$ Existen situaciones bastante curiosas en donde ambos parlamentarios se encuentran presentes el día de la votación y a la vez están pareados. Esto ocurre porque registran su llegada y a posteriori se retiran, así no complican a sus respectivas bancadas a la hora de votar. ${ }^{7}$ Esta institución dentro del Congreso Nacional es un fiel ejemplo de que, a pesar de las diferencias ideológicas o partidarias, los parlamentarios tienden a la coordinación.

$4 \quad$ Uno de los principales ejemplos de esta situación fue lo sucedido con el diputado DC Pablo Lorenzini, el cual no siguió las indicaciones partidarias y perdió su puesto en la comisión de hacienda.

5 Se cataloga a los partidos como oficialistas o de oposición pensando en los 20 años de gobierno de la Concertación. A partir de marzo de 2010 estos roles se modificaron.

Biblioteca del Congreso Nacional.

Para un ejemplo concreto se puede observar en la sesión 31 de la legislatura 338 en donde los diputados Pía Guzmán (UDI) y Aldo Cornejo (DC) se encuentran presentes pero a la vez pareados. 
Otra institución muy poco analizada dentro del Congreso y que permite evidenciar cómo los parlamentarios cooperan entre ellos independientemente de su afiliación partidaria o sus preferencias ideológicas es la hora de incidentes. Esta instancia es el momento en donde los congresistas ofician a miembros del Ejecutivo para pedir recursos, explicaciones o cambios en sus distritos. Aquí es posible observar el credit claiming y el constituency service de parte de los diputados. ${ }^{8}$ Sin embargo, es el momento en donde los parlamentarios pueden ejercer su rol fiscalizador y crítico frente a la gestión del Ejecutivo, independientemente de que los temas tiendan a tener un carácter más distrital que nacional. Más del $90 \%$ de los oficios van dirigidos hacia alguna entidad del Ejecutivo y en términos críticos a su labor. Al finalizar cada parlamentario su exposición, existe la instancia de adherir a lo propuesto. Aquí es posible ver que en más del 50\% de los casos se trata de una adhesión o apoyo intercoalicional. ${ }^{9}$ Por ende, es posible extraer dos conclusiones importantes en la hora de incidentes: (1) Es evidente un alto nivel de cuestionamiento a la gestión del Ejecutivo, independientemente de si es un diputado oficialista o de oposición. (2) Existe un importante apoyo entre diputados de diferentes bancadas que busca darle mayor peso político a sus oficios, debido a que éstos solo deben ser respondidos por escrito y no implican que el Ejecutivo deba tomar medidas específicas.

Es posible extraer dos conclusiones sobre la coordinación parlamentaria, en primer lugar se evidencia la importancia que tienen los partidos políticos en el comportamiento de sus legisladores, éstos tienden al orden a pesar de algunas excepciones que no perturban la norma. En segundo lugar, el Congreso como institución ha sido capaz de ir ganando autonomía e independencia frente a los amplios poderes del Ejecutivo. Esto gracias a que sus actores no operan como entes dispersos sino que son capaces de coordinarse independiente de sus intereses partidarios e ideológicos, siendo notable cómo se interrelacionan las necesidades y obligaciones partidarias (disciplina) con las parlamentarias (coordinación). La importancia de los partidos políticos dentro de la legislatura permite el posterior éxito de la coordinación parlamentaria, ya que evita la atomización de los funcionarios. Ahora es necesario complementar el desarrollo de la coordinación con los indicadores que demuestran una mayor productividad y el análisis de las circunstancias y momentos más proclives para ésta.

\section{NUEVAS VARIABLES EXPLICATIVAS}

Desde el retorno a la democracia en 1990 el Congreso Nacional no ha sufrido una alteración significativa en su composición partidaria. Los dos principales bloques políticos -la Alianza por Chile y la Concertación- han mantenido medianamente estable su contingente legislativo, gracias a los incentivos que genera el Sistema Binominal en la

8 Tanto el credit claiming como el constituency service logran conciliarse con el objetivo de desarrollo institucional que tiene el Congreso.

9 La base de datos en donde se extrajeron estas conclusiones fue realizada en el marco del proyecto "Auditoría de la Democracia" (PNUD), la interpretación corresponde al autor. 
distribución de fuerzas partidarias dentro del Congreso, permitiendo un mapeo bipolar de los parlamentarios (Alemán y Saiegh, 2007). La Concertación ha logrado obtener una leve mayoría en la Cámara Baja en todas las elecciones desde 1989; sin embargo, en el Senado se encontró en minoría parlamentaria producto de la existencia de senadores designados, enclave autoritario que llegó a su fin con las reformas constitucionales del 2005. ${ }^{10}$

Sucede algo similar con los niveles de disciplina partidaria; los trabajos realizados para los períodos 1994-1998 (Carey, 2002) y para el período 2002-2006 (Toro, 2007) nos muestran resultados muy similares entre sí, permitiendo reafirmar la idea de estabilidad. La Concertación se ha caracterizado por presentar mayores niveles de disciplina que la Alianza, y dentro de esta última es la UDI la que destaca en desmedro de su compañero de coalición RN, que se ha transformado en un partido pivote para que el Ejecutivo pueda aprobar sus iniciativas (Toro, 2007).

En términos de poderes presidenciales legislativos, éstos se caracterizan por sus altas prerrogativas en desmedro de las capacidades del Parlamento. El presidente en Chile cuenta tanto con poderes proactivos (alterar el statu quo) como reactivos (mantener el statu quo). Estas capacidades presidenciales no se han visto alteradas desde 1990, siendo sutilmente matizadas con las reformas constitucionales en el 2005 (Berríos y Gamboa, 2006) que le entregaron algunas capacidades nuevas al Congreso pero que no logran superar lo simbólico. ${ }^{11}$ Por ende, los poderes presidenciales se han mantenido prácticamente intactos desde 1990 hasta el 2005 y las reformas posteriores no significaron un cambio importante en el juego de poderes entre el Ejecutivo y el Legislativo. ${ }^{12}$ Solo una de éstas podría traer beneficios para el Parlamento en el balance de poderes, la reducción del período presidencial de seis a cuatro años implica que el Ejecutivo tiene menos tiempo para llevar a cabo su agenda legislativa. Mientras que los parlamentarios, producto de la alta tasa de reelección y coordinación, pueden mantener su agenda a través de diferentes períodos legislativos.

El último factor de estabilidad en la relación entre ambos poderes se debe a que desde el retorno a la democracia la Concertación ha logrado controlar el Ejecutivo, permitiendo que en los últimos 20 años fueran los mismos partidos políticos los que ocuparan el rol de oposición y de oficialismo dentro del Congreso Nacional. Esto recién se vio alterado tras las elecciones presidenciales del 2010.

En síntesis, podemos afirmar que la composición de fuerzas, la disciplina partidaria, los poderes presidenciales y los roles dentro del Congreso no han sufrido variaciones considerables desde 1990 hasta el 2009. Por lo tanto, la estabilidad dentro de las atribuciones

10 Este trabajo no incluye los resultados de la elección parlamentaria de diciembre del 2009, en donde la Alianza por primera vez en la historia democrática logra obtener mayoría en la Cámara Baja.

11 El ejemplo más característico es la interpelación a ministros, la cual no supera el show mediático y es incapaz de funcionar como un verdadero voto de censura ministerial.

12 Una de las reformas de mayor importancia para el Congreso Nacional fue el fin de los senadores designados. 
y características de los funcionarios legislativos es uno de los componentes esenciales del Parlamento en las últimas dos décadas. Mientras que el presidente en Chile no ha perdido poder en términos significativos con las reformas de 1989 y 2005 . No obstante, la estabilidad de las instituciones no implica que éstas no se encuentren en permanente cambio (North, 1993).

Esta estabilidad no se ve reflejada en la producción legislativa, la cual ha sufrido importantes variaciones a lo largo de los años. El Cuadro 1 muestra la cantidad y el porcentaje de leyes aprobadas y presentadas, tanto de mensajes como de mociones.

Es posible identificar una importante variación entre mociones y mensajes aprobados año a año (la desviación estándar supera los nueve puntos porcentuales). Por ende, surge la necesidad de probar nuevas variables que nos permitan comprender de mejor manera la conducta legislativa cuando la composición, la disciplina y los poderes del Congreso se han mantenido relativamente estables desde el retorno a la democracia.

Es interesante comprobar si el número de mociones aprobadas se relaciona con el porcentaje de mociones aprobadas (Gráfico 1), lo que permite evidenciar si el aumento de mociones se debe a un año particularmente activo en materia legislativa para ambos poderes o solo para el Congreso, ya que no es descabellado pensar que cuanto más mociones se aprueban también sucede con los mensajes.

Se observa que la relación entre el porcentaje y el número de mociones aprobadas es positiva. Indicando claramente que mientras más mociones son aprobadas menor es el peso que tienen los mensajes presidenciales dentro de las leyes aprobadas. Además, dentro del grupo de las leyes presentadas es posible constatar que las mociones han presentado una tendencia creciente a través de los años, todo lo contrario en el caso de los mensajes.

Sin embargo, este mayor número de leyes aprobadas puede tener solo un carácter simbólico y no implicar una real relevancia en la arena política. Para evitar este inconveniente se clasificaron todas las mociones aprobadas de acuerdo a su nivel de relevancia. Este tipo de trabajo fue realizado por Mayhew (1991) para evaluar la productividad legislativa bajo períodos de gobierno divididos. ${ }^{13}$ Existen diferentes metodologías para realizar esta labor (Howell et al., 2000); sin embargo, cada Congreso posee sus propias particularidades, siendo compleja la importación de otras clasificaciones (Gamboa y Berríos, 2006). En esta investigación se utilizó un puntaje de 1 a $4{ }^{14}$ codificando todas las mociones aprobadas desde marzo de 1990 hasta marzo de 2010. El criterio de codificación se explica en el Cuadro 2.

13 Otro ejemplo de clasificación de leyes es el utilizado por Blondel (1990) y Gamboa y Berríos (2006), distinguiendo tres tipos de leyes: distributivas, regulatorias y redistributivas.

14 Se utilizan pocas categorías ya que no se desea analizar en profundidad la relevancia de las leyes, sino que ser capaz de observar si ha evolucionado el desarrollo productivo del Congreso. 


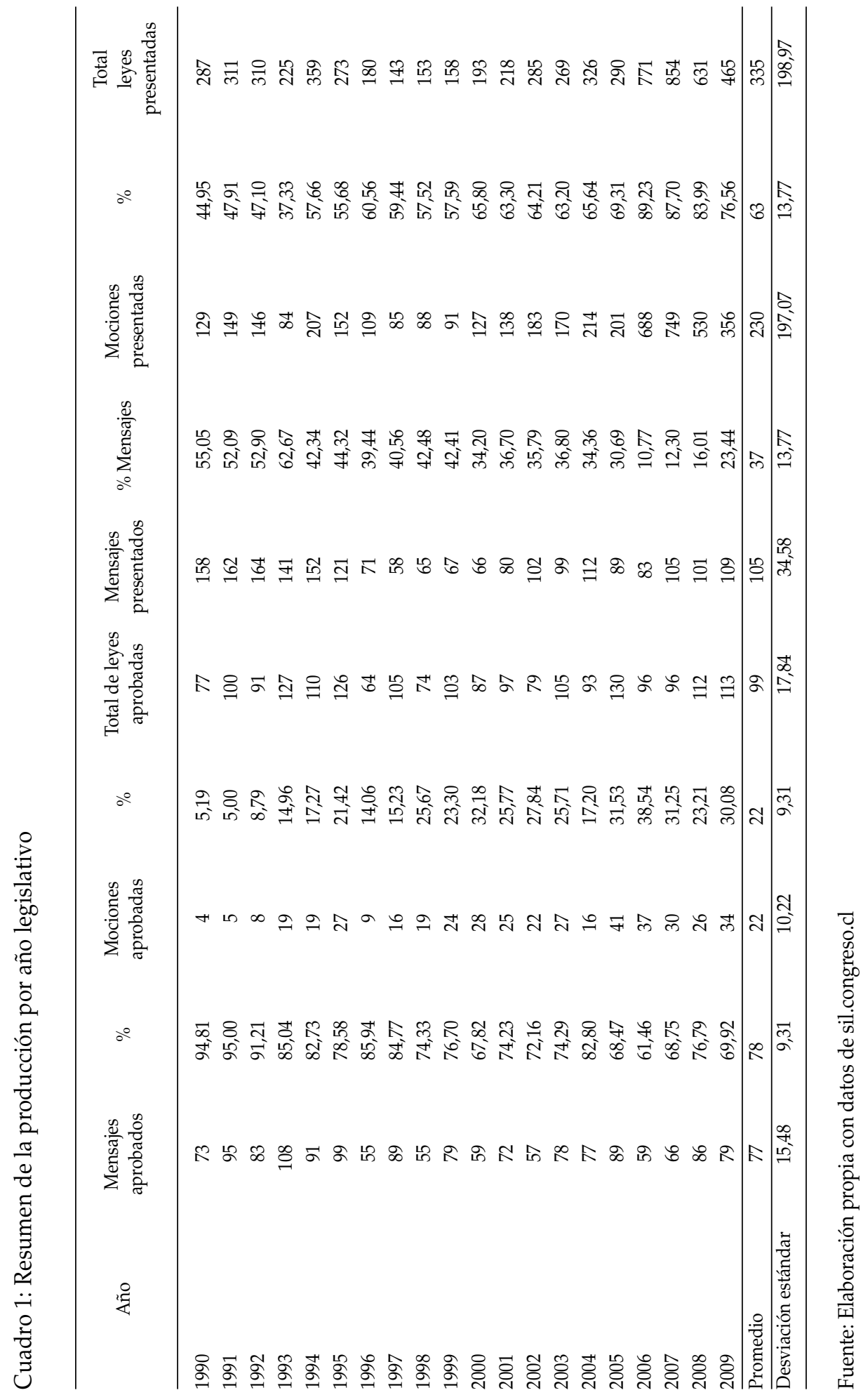


Gráfico 1: Relación entre el número de mociones aprobadas y el porcentaje de mociones aprobadas

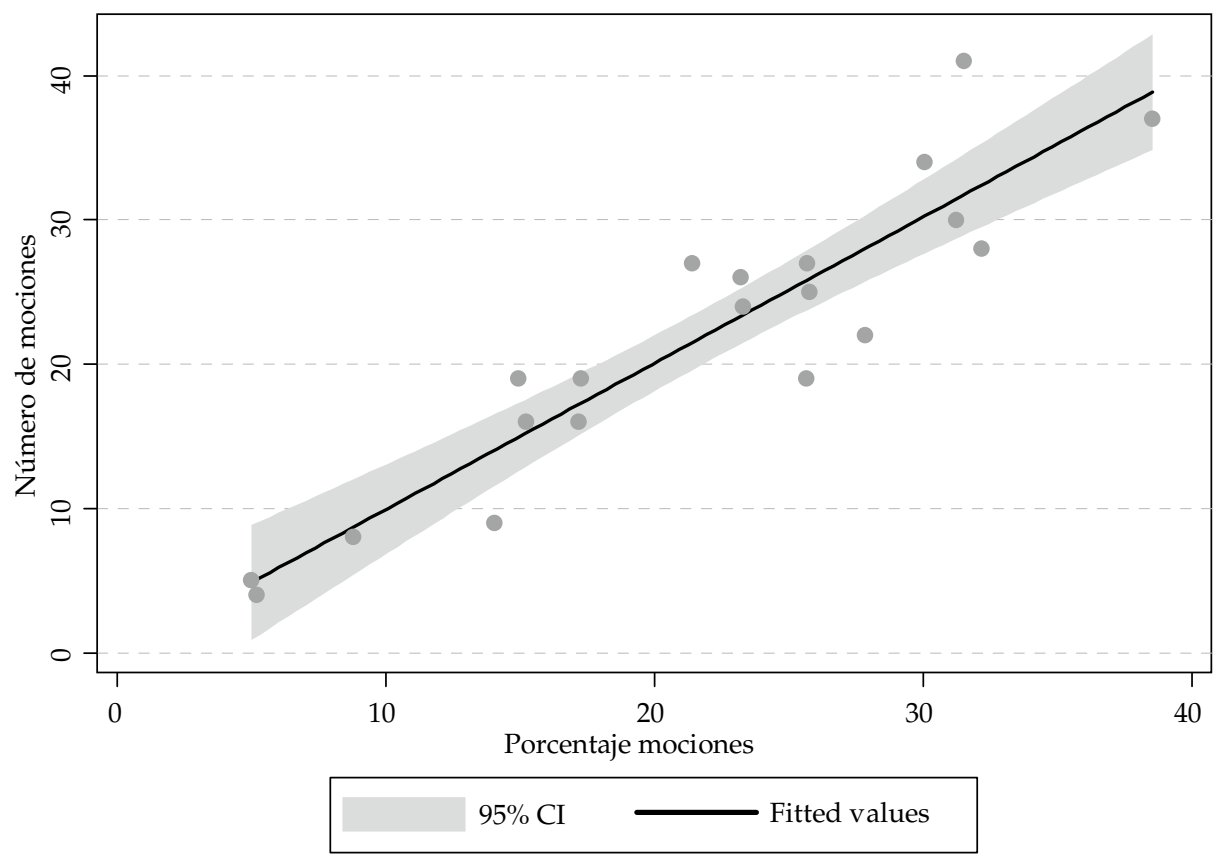

Fuente: Elaboración propia.

Cuadro 2: Criterio de codificación para la relevancia de las mociones aprobadas

Puntaje Criterio

1 Monumentos, nacionalizaciones (personas) y feriados.

Leyes de carácter local (regiones, provincias o comunas), particulares (modificación

2 de fechas o plazos) y relativas a grupos pequeños en relación al total de la población (pescadores artesanales, mineros del carbón, etc.).

Leyes de carácter nacional (derecho de los trabajadores, civiles o penales, etc.), temáticas

3 generales relevantes (educación, salud, empleo, etc.) y relativas a un grupo significativo en relación al total de la población (mujeres, microempresarios, etc.).

4 Reformas constitucionales.

El siguiente cuadro resume la información codificada de mensajes y mociones, mostrando el promedio de relevancia por año legislativo. 
Cuadro 3: Importancia de las mociones por año

\begin{tabular}{|c|c|c|c|c|c|}
\hline Año & $\begin{array}{c}\text { Relevancia } \\
\text { mociones }\end{array}$ & $\begin{array}{c}\text { Relevancia } \\
\text { mensajes }\end{array}$ & $\begin{array}{l}\text { Primer } \\
\text { año de } \\
\text { gobierno }\end{array}$ & $\begin{array}{c}\text { Elecciones } \\
\text { Parlamentarias }\end{array}$ & $\begin{array}{l}\text { Presidente } \\
\text { de turno }\end{array}$ \\
\hline 1990 & 1,25 & 2,29 & 1 & 0 & Patricio Aylwin \\
\hline 1991 & 1,80 & 2,10 & 0 & 0 & Patricio Aylwin \\
\hline 1992 & 2,50 & 2,27 & 0 & 0 & Patricio Aylwin \\
\hline 1993 & 1,88 & 2,27 & 0 & 1 & Patricio Aylwin \\
\hline 1994 & 2,00 & 2,47 & 1 & 0 & Eduardo Frei \\
\hline 1995 & 2,11 & 2,29 & 0 & 0 & Eduardo Frei \\
\hline 1996 & 2,67 & 2,42 & 0 & 0 & Eduardo Frei \\
\hline 1997 & 1,88 & 2,44 & 0 & 1 & Eduardo Frei \\
\hline 1998 & 2,11 & 2,29 & 0 & 0 & Eduardo Frei \\
\hline 1999 & 2,00 & 2,33 & 0 & 0 & Eduardo Frei \\
\hline 2000 & 2,46 & 2,28 & 1 & 0 & Ricardo Lagos \\
\hline 2001 & 2,36 & 2,39 & 0 & 1 & Ricardo Lagos \\
\hline 2002 & 2,45 & 2,40 & 0 & 0 & Ricardo Lagos \\
\hline 2003 & 2,11 & 2,36 & 0 & 0 & Ricardo Lagos \\
\hline 2004 & 2,19 & 2,32 & 0 & 0 & Ricardo Lagos \\
\hline 2005 & 2,39 & 2,40 & 0 & 1 & Ricardo Lagos \\
\hline 2006 & 2,57 & 2,37 & 1 & 0 & Michelle Bachelet \\
\hline 2007 & 2,20 & 2,46 & 0 & 0 & Michelle Bachelet \\
\hline 2008 & 2,04 & 2,36 & 0 & 0 & Michelle Bachelet \\
\hline 2009 & 2,18 & 2,46 & 0 & 1 & Michelle Bachelet \\
\hline Promedio & 2,16 & 2,35 & - & - & - \\
\hline $\begin{array}{l}\text { Desviación } \\
\text { estándar }\end{array}$ & 0,32 & 0,09 & - & - & - \\
\hline
\end{tabular}

Fuente: Elaboración propia.

Se muestra una interesante variación, evidenciando que la importancia de las leyes emanadas del Congreso no ha sido constante a lo largo de los años. ${ }^{15}$ Ahora es necesario investigar en cuáles instancias el Parlamento intenta ser más productivo.

\section{a. Los ciclos políticos: elecciones parlamentarias y primer año de gobierno}

Los congresistas buscan instancias dentro del ciclo político para aumentar sus niveles de productividad, una de éstas son los años de elecciones parlamentarias. Durante este período los legisladores deben jugarse el escaño e intentar permanecer en el Congreso.

15 Es complejo determinar cuál es el índice ideal para determinar si un Congreso es relevante en términos de policymaking. 
Esto crea la necesidad de mostrarse productivo y eficiente, ya que un Congreso que se encuentra sometido a las potestades presidenciales está lejos de la figura de productividad. Podría contraargumentarse que los legisladores utilizan otras técnicas para asegurar su reelección, como por ejemplo prácticas clientelares (Luna, 2008). Sin embargo, éstas pueden complementarse con el trabajo legislativo propiamente tal, sobre todo a la hora de realizar credit claiming. La única manera de mostrar logros es teniéndolos, es decir, aprobando materias de ley propias del Congreso. ${ }^{16}$ Además, este es el momento en donde se ejerce accountability con los electores (Mayhew, 1974). El hecho de poder reelegirse le entrega a los parlamentarios un incentivo poderoso para aumentar la productividad y ser vistos como agentes gravitantes en la arena política por los constituencies. En este contexto cobra importancia la coordinación parlamentaria, en donde la premisa de la ambición se hace evidente: los legisladores estructuran su comportamiento en función de la reelección (Mayhew, 1974) y, además, lo hacen coordinadamente. La evidencia del aumento de institucionalización del Congreso chileno permite creer que los legisladores son capaces de imponer su propia agenda legislativa en las instancias en donde es necesario, principalmente cuando deben pelear sus escaños para continuar en el Parlamento.

En el primer año de gobierno también se dan ciertas condiciones institucionales para que el Congreso pueda mantener altos niveles de productividad. Este aspecto resulta contraintuitivo a primera vista ya que este período tiende a observarse como una "luna de miel" para el Ejecutivo. Las causas que explican el aumento de productividad del Parlamento pueden explicarse bajo la lógica de lo nuevo versus lo antiguo: lo nuevo es el gobierno que recién comienza su mandato y está aprendiendo las lógicas administrativas y lo antiguo al Legislativo que gracias a la reelección y el alto nivel de éxito de los incumbents mantiene su esencia, elección tras elección. En términos de teoría de juegos, el Parlamento se encuentra en una situación de juego repetido en donde puede optimizar sus utilidades ya que maneja información más acabada, en cambio, el Ejecutivo participa en el juego por primera vez y carece de información relevante. Por lo tanto, el primer año de gobierno -a pesar de ser conocido como luna de miel para el Ejecutivo- implica una oportunidad institucional importante para el Congreso. Éste puede aprovechar la inexperiencia del nuevo gobierno y a través de acciones coordinadas aprobar más proyectos de ley propios. ${ }^{17}$ Podría contraargumentarse que la Concertación ha mantenido al Ejecutivo en los últimos veinte años, sin embargo, los funcionarios de confianza (ministros y subsecretarios) son renovados de un gobierno a otro.

\section{b. Proceso institucional de largo plazo: la acumulación de experiencia democrática del Congreso}

En términos prácticos, las capacidades de cualquier Congreso están circunscritas a lo estipulado por la Constitución; estas potestades institucionales permiten discriminar

16 El trabajo legislativo no es solo aprobar proyectos de ley. Realizar indicaciones o enmiendas también es una forma de influir sobre el proceso legislativo, sobre todo cuando son mensajes presidenciales.

17 El año 1990 no se considera metodológicamente como primer año de gobierno, ya que no se puede aplicar la lógica nuevo versus antiguo cuando ambos poderes se estrenaban junto a la nueva democracia. 
entre un Parlamento fuerte o débil en poderes reactivos o proactivos. Sin embargo, el centrarse solo en lo legal y constitucional puede derivar en sesgos y errores, ya que las habilidades legislativas van más allá que lo escrito. Si el Congreso presenta bajos niveles de disciplina o si no es capaz de actuar coordinadamente frente el Ejecutivo, lo que diga la Constitución puede quedar solo en el papel. Cuando hablamos de poderes legislativos nos referimos también a las habilidades que tienen los parlamentarios para actuar de forma coordinada y de esta manera lograr un mayor poder institucional, entendido como un proceso gradual y acumulativo. Este proceso posee dos condiciones necesarias, la primera es que exista la reelección y la segunda es que la tasa de incumbents exitosos sea alta. Un Congreso que posee funcionarios con experiencia implica que estos pueden desarrollar un poder no constitucional, expresado en el conocimiento de la relación entre ambos poderes del Estado y en las habilidades para cooperar entre bancadas diferentes, con el objetivo de potenciar los proyectos de ley propios. En palabras de North (1993: 17): Las limitaciones informales encajadas en costumbres, tradiciones y códigos de conducta son mucho más resistentes o impenetrables a las politicas deliberadas. Las investigaciones sobre incumbencia en Chile han arrojado que los parlamentarios que vuelven a competir por su escaño poseen una probabilidad bastante alta de conseguir su objetivo (Díaz et al., 2006; Navia, 2008). Este aspecto es fundamental, ya que la reelección debe ser aprovechada por los parlamentarios de forma eficiente. Cuando un parlamentario es capaz de volver a competir por su escaño se generan los incentivos suficientes para ser más eficaz en su labor legislativa y además profesionaliza su carrera, ya que va adquiriendo habilidades período tras período y la legislatura en su conjunto se vuelve cada vez más experta y capacitada. Cuando los parlamentarios deben pelear por su reelección, se ven motivados a cumplir un rol más trascendental dentro de la arena política, ya que sin logros el credit claiming pierde fuerza. Además, la mayoría de los legisladores buscan hacer su carrera política dentro del Congreso (Carey, 2002), no siendo utilizada como plataforma política para cargos de mayor relevancia fuera de la legislatura. Cuando la institución de la reelección no existe, se debilitan tanto los partidos políticos como la labor parlamentaria (Carey, 1996), ya que es muy difícil adquirir las capacidades para funcionar como un cuerpo coherente y coordinado solo en un período legislativo. Para lograr la coordinación requerida se necesita que los actores desarrollen confianza entre ellos, a pesar de la pertenencia a bancadas diferentes. El siguiente gráfico nos muestra cómo ha evolucionado el porcentaje de mociones aprobadas (en relación al total de leyes aprobadas) desde el inicio de la democracia en Chile.

El Gráfico 2 permite confirmar los planteamientos sobre la reelección y la incumbencia. Los parlamentarios han logrado aumentar sus capacidades legislativas a pesar de que constitucionalmente no han existido cambios o reformas importantes que lo permitan. Esto se explica por la capacidad de coordinación y cooperación, una especie de complicidad parlamentaria que busca una mayor gravitancia del Poder Legislativo. Este proceso puede denominarse como acumulación de experiencia democrática. Podría contraargumentarse que la Concertación ha permitido este aumento de la productividad ya que controla la Cámara Baja desde 1990. Sin embargo, con la existencia de los senadores institucionales o designados hasta el año 2005 la derecha tenía el control en la Cámara Alta. Por ende, 
Gráfico 2: Mociones aprobadas desde 1990 hasta el 2009 (Dividido por gobierno)

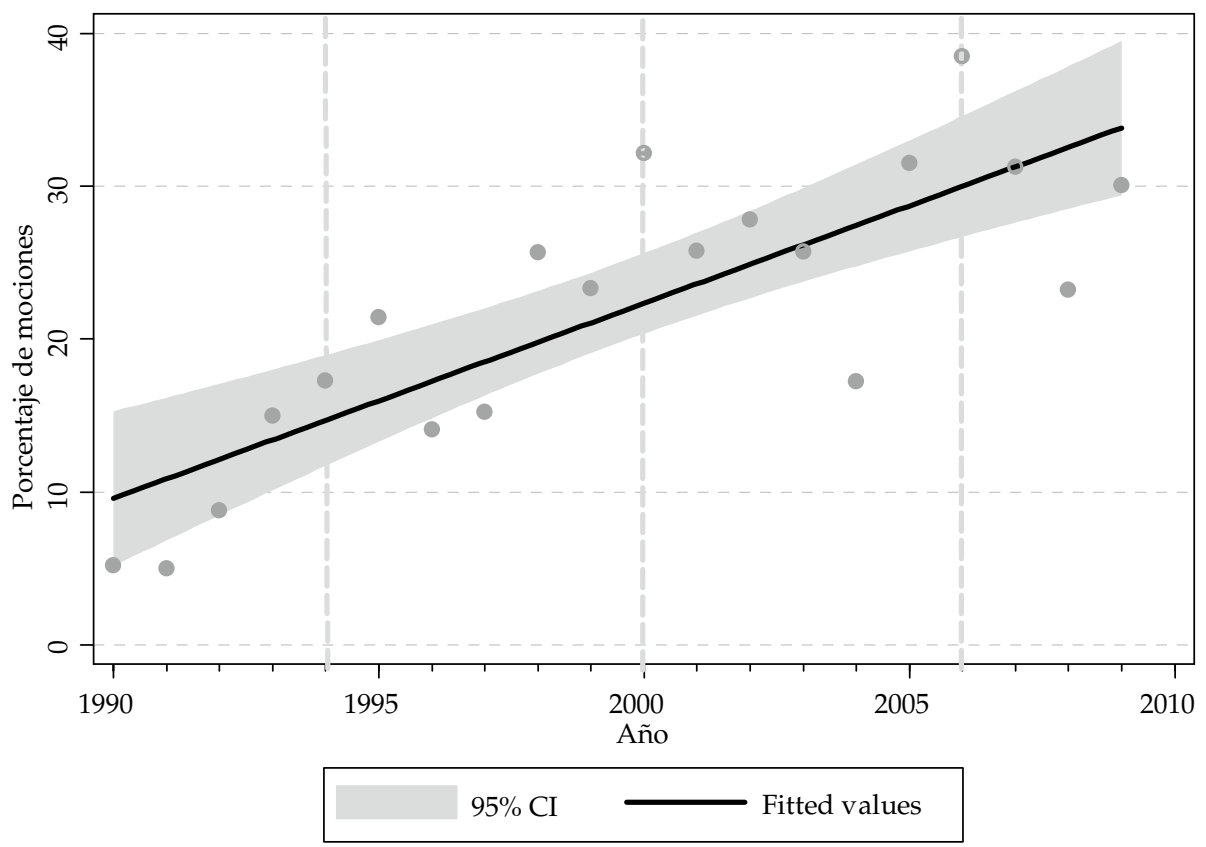

Fuente: Elaboración propia.

la coordinación a nivel intercoalicional era condición necesaria y suficiente para el desarrollo legislativo y el aumento de la productividad.

Es necesario también observar si la relevancia de las mociones ha aumentando a lo largo de los años. El Gráfico 3 intenta dar pistas sobre este punto.

Es posible sacar algunas conclusiones del gráfico, ya que se evidencia un aumento de la importancia de las mociones desde $1990 .{ }^{18}$ La pendiente de la curva no es muy marcada por la escasa variabilidad entre las categorías, pero lo suficiente para marcar una tendencia.

El gobierno que presenta el menor índice de productividad legislativa es el de Patricio Aylwin, debido a que en este período el Congreso Nacional presentaba altas tasas de inexperiencia producto de su desaparición durante los años de autoritarismo y a que las capacidades para coordinarse y resolver dilemas de acción colectiva van generándose a través de la práctica. Por ejemplo, las leyes emanadas de parlamentarios en este período no fueron de gran importancia o relevancia nacional, en donde primaron las nacionalizaciones por gracia, los feriados y la erección de monumentos (Berríos y 
Gráfico 3: Relevancia de las mociones desde 1990 hasta 2009

(Dividido por gobierno)

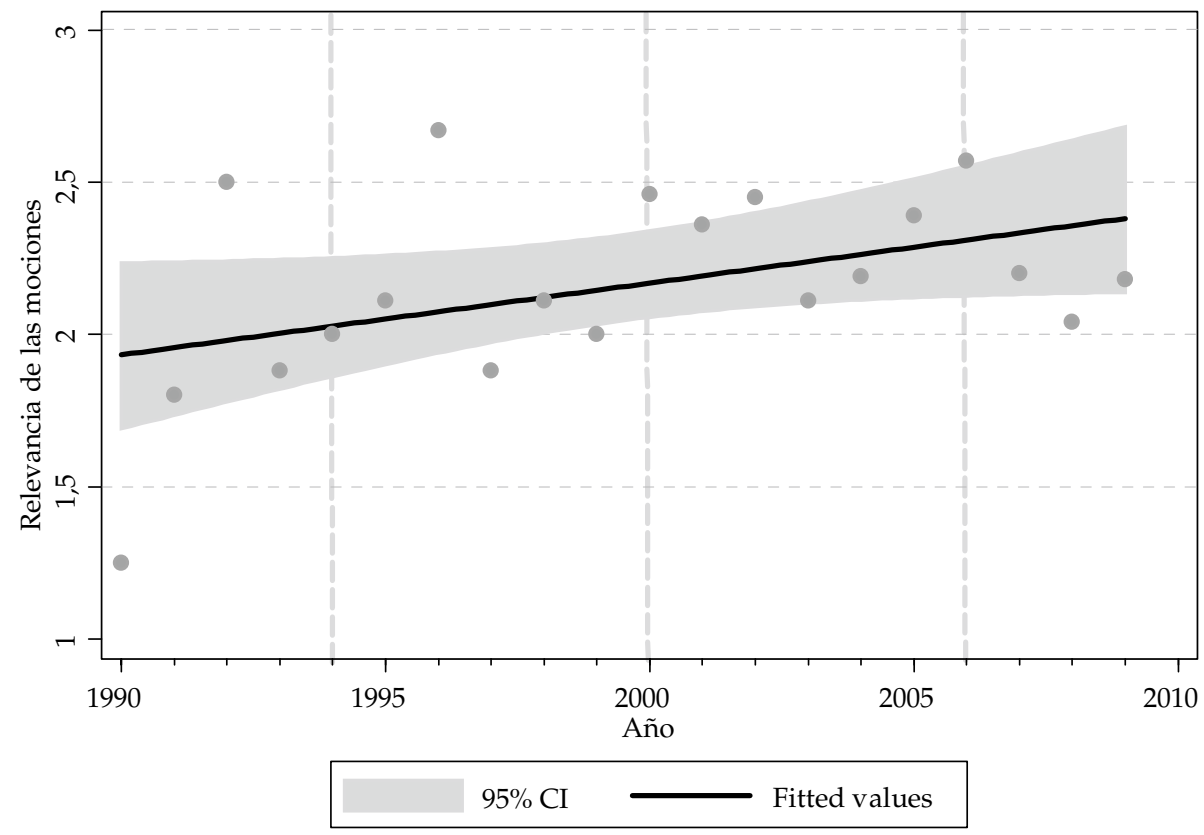

Fuente: Elaboración propia.

Gamboa, 2006). Es necesario tener en cuenta que los partidos se encontraban en una fase de reestructuración y su influencia sobre los parlamentarios era menor.

Es posible afirmar que el Congreso en Chile ha aumentado su productividad ya que se aprueba un mayor número de mociones y éstas tienen mayor relevancia política que al inicio de la democracia. Esto confirma lo planteado por Berríos y Gamboa (2006: 15) tras un estudio de las leyes aprobadas por la legislatura: es posible advertir un cambio cualitativo en la legislación emanada del Parlamento.

\section{ANÁLISIS ESTADÍSTICO}

Para la comprobación de la hipótesis se utilizarán dos modelos, una regresión logística y otra de mínimos cuadrados. El modelo logit tiene como objetivo evidenciar la instancia en donde la legislatura es más productiva en términos cuantitativos, es decir, cuando aprueba más mociones independientemente de su relevancia. Por lo tanto, la variable dependiente corresponde a todas las leyes aprobadas desde marzo de 1990 hasta febrero de 2010, codificadas como 1 si su origen se encuentra en el Parlamento (mociones) y 0 si provienen desde el Ejecutivo (mensajes). En cambio, el segundo modelo de regresión (OLS) está diseñado para evaluar la relevancia de las leyes a través de la codificación ya presentada. La variable dependiente en este caso irá desde 0 hasta 4 , siendo un 0 los mensajes y desde el 1 hasta 4 las mociones según su grado de importancia política. 
Las variables independientes desagregadas de la hipótesis son tres: elecciones parlamentarias, primer año de gobierno y acumulación de experiencia democrática. Para el caso de primer año de gobierno no se contabiliza el primer año desde el retorno a la democracia ya que la teoría nos dice que aún no existe el dilema de lo antiguo versus lo nuevo, puesto que ningún actor posee aún experiencia política democrática luego del período autoritario. Las dos primeras corresponden a variables dicotómicas y la tercera se mide desde 1 a 20, de acuerdo a la antigüedad de la democracia reinstaurada en 1990.

Como hipótesis alternativas se agregan las variables último año de gobierno y aprobación presidencial, ${ }^{19}$ pensando que éstas podrían influir en los niveles de productividad del Congreso. La variable elecciones parlamentarias puede generar multicolinealidad con último año de gobierno (tres elecciones concurrentes), por lo tanto se establecen dos modelos, el primero de ellos no testea esta variable.

Además, no se pueden dejar de lado las variables de carácter partidario. Por ende, se incorpora Concertación Senado, que corresponde al contingente legislativo que poseía la Concertación durante los cinco períodos legislativos estudiados, medido en número de escaños. ${ }^{20}$ No se incorpora la Cámara Baja ya que la mayoría parlamentaria se mantuvo constante desde 1990, lo que no sucedió en la Cámara Alta producto de los senadores designados o institucionales.

Cuadro 4: Regresión logística

\begin{tabular}{lcc}
\hline \multicolumn{1}{c}{ Mociones } & Modelo 1 & Modelo 2 \\
\hline Primer año & $.648^{* * *}$ & $.622^{* * * *}$ \\
& $(.157)$ & $.158)$ \\
Último año & - & .239 \\
& - & $(.145)$ \\
Aprobación & -.008 & -.008 \\
& $(.005)$ & $(.005)$ \\
Elecciones & $.332^{*}$ & - \\
& $(.143)$ & - \\
Acumulación & $.078^{* * *}$ & $.077^{* * *}$ \\
& $(.010)$ & $(.010)$ \\
Concertación & .065 & .059 \\
& $(.037)$ & $(.037)$ \\
Constante & $-3.291^{* * *}$ & $-3.158^{* * *}$ \\
& $(.877)$ & $(.893)$ \\
Observaciones & 1986 & 1986 \\
Log likelihood & -1005.7978 & -1007.1051 \\
RT chi2 & $78.95^{* * *}$ & $76.34^{* * *}$ \\
\hline
\end{tabular}

${ }^{*} \mathrm{p} \leq .05,{ }^{* *} \mathrm{p}<.01,{ }^{* * *} \mathrm{p}<.001$. Error estándar entre paréntesis.

Fuente: Elaboración propia.

19 Resultados de la encuesta CEP.

20 Corresponden a los senadores electos y designados pertenecientes a la Concertación. No se incorpora una variable Alianza Senado ya que está altamente correlacionada con los escaños concertacionistas. 
Cuadro 5: Regresión lineal de mínimos cuadrados (OLS)

\begin{tabular}{lcc}
\hline \multicolumn{1}{c}{ Relevancia } & Modelo 1 & Modelo 2 \\
\hline Primer año & $.303^{* * *}$ & $.288^{* * *}$ \\
& $(.067)$ & .067 \\
Último año & - & .060 \\
& - & .058 \\
Aprobación & -.003 & -.002 \\
& $(.002)$ & .002 \\
Elecciones & $.115^{*}$ & - \\
& $(.058)$ & - \\
Acumulación & $.030^{* * *}$ & $.030^{* * *}$ \\
Concertación & $(.003)$ & .003 \\
Constante & .029 & .027 \\
& $(.015)$ & .016 \\
& -.380 & -.349 \\
Observaciones & $(.372)$ & .378 \\
F & & 1986 \\
\hline
\end{tabular}

${ }^{*} \mathrm{p} \leq .05,{ }^{* *} \mathrm{p}<.01,{ }^{* * *} \mathrm{p}<.001$. Error estándar entre paréntesis.

Fuente: Elaboración propia.

Los resultados arrojan significancia estadística en las tres variables independientes que se derivan de la hipótesis, no en el caso de las variables alternativas que al parecer no afectarían el comportamiento legislativo. Con esto se demuestra que el Congreso Nacional es capaz de coordinarse para aumentar su productividad cuando observa que el Ejecutivo se encuentra debilitado producto del inicio de su mandato, cuando existen elecciones parlamentarias y es necesario el credit claiming y gracias a un proceso de largo plazo, que es la acumulación de experiencia de los legisladores.

A pesar de la comprobación de la hipótesis inicial, es necesario asumir ciertas limitaciones de esta investigación. Primero, es posible que exista un problema de autocorrelación entre las variables independientes, ya que estas abarcan años completos. En segundo lugar, es evidente que no se estudiaron las leyes presentadas, que también sufren una variación año a año y podrían poseer diferentes variables explicativas que las leyes aprobadas. Sin embargo, como intentamos medir productividad legislativa es necesario acotar el campo de estudio a las materias de ley que fueron aceptadas en el Congreso y que, por ende, fueron exitosas y no meramente simbólicas o especulativas. Aunque el análisis de las leyes rechazadas se vuelve un interesante campo de estudio para futuras investigaciones. 


\section{CONCLUSIONES}

Después de 20 años de gobierno democrático era necesario analizar el comportamiento del Poder Legislativo desde una perspectiva diacrónica y a través de nuevas variables explicativas. Este artículo se suma a una importante construcción teórica sobre el Congreso Nacional, la cual ha ido otorgándole cada vez más atribuciones y capacidades, a pesar de sus debilidades constitucionales frente al Ejecutivo. El análisis desarrollado pretendió incorporar al estado del arte una nueva forma de evaluar la productividad parlamentaria para el caso chileno, analizando las mociones aprobadas en relación al total de leyes superando las limitaciones de estudios anteriores, que solo analizan a uno de los dos poderes, por ejemplo comparando mensajes aprobados con mensajes presentados.

Con la relativización de la tesis de Linz (1978) sobre las debilidades estructurales de los presidencialismos (Shugart y Carey, 1992; Cheibub, 2007), es de esperar que los estudios legislativos tiendan a analizar la relación entre ambos poderes de forma más amplia y bidireccionalmente. El Congreso Nacional no estructura su conducta como un obstaculizador o un rubber stamp, sino que intenta potenciar sus capacidades a pesar de las limitadas prerrogativas con que cuenta. Para observar esto es necesario reconocer que los legisladores poseen motivaciones que trascienden las locales y las partidarias. Éstas se estructuran en objetivos colectivos, en donde se busca el desarrollo institucional a través del aumento de la productividad y explicado por el desarrollo de la coordinación.

Los resultados empíricos y el análisis teórico nos permiten evidenciar que el Legislativo es capaz de coordinar intereses y aumentar su influencia a lo largo de los años, siempre teniendo dos objetivos en mente: aumentar su productividad como institución y conseguir la reelección en el cargo. En donde la coordinación entre los parlamentarios de diferentes bancadas y partidos es la piedra angular para el éxito legislativo. El Parlamento se comporta como una institución coherente y bajo una lógica de elección racional en donde se intentan maximizar las utilidades y solucionar de manera más eficiente los dilemas de acción colectiva que se presentan.

Sin embargo, los poderes presidenciales siguen siendo lo suficientemente fuertes para mantener la preponderancia del Ejecutivo en materias legislativas, aunque ésta ha ido retrocediendo gradualmente con el paso de los años, en donde la institución de la reelección es pieza clave y fundamental en el desarrollo legislativo. La relación entre ambos poderes puede observarse como una balanza, con una fuerte inclinación hacia el Ejecutivo producto de los privilegios constitucionales. Sin embargo, en ciertas instancias del ciclo político y bajo un proceso institucional de largo plazo, el Legislativo es capaz de ganar peso específico e intentar la búsqueda del equilibrio que aún no se alcanza totalmente. 


\section{REFERENCIAS}

Alemán, Eduardo y Sebastián Saiegh. 2007. "Legislative Preferences, Political Parties, and Coalition Unity in Chile". Comparative Politics 39 (3): 253-272.

Alemán, Eduardo y Patricio Navia. 2009. “Legislative Success in 'Strong' Presidential Systems: Institutional Influences and the Fate of Government Bills in Chile". The Journal of Legislative Studies 15 (4): 401419.

Alemán, Eduardo y Ernesto Calvo. forthcoming. "Unified Government, Bill Approval, and the Legislative Weight of the President". Comparative Political Studies.

Altman, David y Daniel Chasquetti. 2005. "Re-Election and Political Career Paths in the Uruguayan Congress: 1985-1999". The Journal of Legislative Studies 11 (2): 235-253.

Altman, David. 2008. "Regímenes de gobierno y sistema de partidos en Chile". En Reforma de los Partidos Politicos en Chile, editado por A. Fontaine, I. Walter, J. Navarrete, C. Larroulet. Santiago: PNUD, 41-74.

Banco Interamericano de Desarrollo (BID). 2006. The Politics of Policies, Economic and Social Progress in Latin America. Washington D.C, Inter-American Development Bank.

Berríos, Fabiola y Ricardo Gamboa. 2006. "El Congreso Nacional chileno y el ejercicio de sus funciones legislativa y fiscalizadora". Politica 47: 99-125.

Blondel, Jean. 1990. "Legislative Behavior: Some Steps Towards a Cross-national Measurement". En Legislatures, editado por Philip Norton. New York: Oxford University.

Boeninger, Edgardo. 2007. Políticas Públicas en Democracia. Institucionalidad y Experiencia Chilena 1990-2006. Santiago: Uqbar.

Bond, Jond, Richard Fleisher y Dan Wood. 2003. "The Marginal and Time-Varying Effects of Public Approval on Presidential Success in Congress". Journal of Politics 65 (1): 92-110.

Calvo, Ernesto. 2007. "The Responsive Legislature: Public Opinion and Law Making in a Highly Disciplined Legislatura". British Journal of Political Science 37: 263-280

Carey, John. 1996. Term Limits and Legislative Representation. Cambridge: Cambridge University Press.

Carey, John. 2002. "Parties, Coalitions, and the Chilean Congress in the 1990s". En Legislative Politics in Latin America, editado por S. Morgenstern y B. Nacif. Cambridge: Cambridge University Press, 222-253.

Chasquetti, Daniel. 2008. Democracia, Presidencialismo y partidos políticos en América Latina: Evaluando la difícil combinación. Montevideo: Ediciones CAUCE.

Cheibub, José Antonio. 2007. Presidentialism, Parliamentarism, and Democracy. New York: Cambridge University Press.

Cox, Gary y Mathew D. McCubbins. 1993. Legislative Leviathan. New York: Cambridge University Press.

Díaz, Diego, Pilar Giannini, Juan Pablo Luna y Rodrigo Núnez. 2006. "El secreto de mi éxito: Seis caminos para llegar y permanecer en Valparaíso". Revista de Ciencia Política 26 (1): 169-182.

Howell, William, Scott Adler, Charles Cameron y Charles Riemann. 2000. "Divided Government and the Legislative Productivity of Congress". Legislative Studies Quarterly 25 (2): 285-312.

Jones, Mark, Sebastián Saiegh, Pablo Spiller y Mariano Tommasi. 2002. "Amateur Legislators Professional Politicians: The Consequences of Party-Centered Electoral Rules in Federal System". American Journal of Political Science 46 (3): 656-669.

Linz, Juan. 1978. The Breakdown of Democratic Regimes: Crisis, Breakdown and Reequilibration. Baltimore: Johns Hopkins University Press.

Londregan, John. 2000. Legislative Institutions and Ideology in Chile. Cambridge: Cambridge University Press.

Luna, Juan Pablo. 2008. "Partidos Políticos y Sociedad en Chile". En Reforma de los Partidos Políticos en Chile, editado por A. Fontaine, I. Walter, J. Navarrete, C. Larroulet. Santiago: PNUD, 75-124.

Mayhew, David. 1974. Congress, The Electoral Connection, New Haven: Yale University Press.

Mayhew, David. 1991. Divided we Govern: Party Control, Lawmaking, and Investigations, 1946-1990. New Haven: Yale University Press.

Morgenstern, Scott. 2002. "Towards a Model of Latin American Legislatures". En Legislative Politics in Latin America, editado por S. Morgenstern y B. Nacif. Cambridge: Cambridge University Press, 222-253. 
Navia, Patricio. 2008. "Legislative Candidate Selection in Chile". En Pathways to Power in Latin America, editado por P. Siavelis y S. Morgenstern. University Park: Penn State University Press, 92-118.

North, Douglass. 1993. Instituciones, cambio institucional y desempeño económico. México. Fondo de Cultura Económica.

Payne, Mark, Daniel Zovatto y Mercedes Mateo Díaz. 2006. La política importa: Democracia y Desarrollo en América Latina. Inter-American Development Bank, International Institute for Democracy and Electoral Assistence.

Programa de las Naciones Unidas para el Desarrollo. Chile (PNUD), forthcoming. "Base Hora de Incidentes". Proyecto Auditoría de la Democracia.

Polsby, Nelson. 1968. "The Institutionalization of the U.S. House of Representatives". American Political Science Review 62 (1): 144-168.

Saiegh, Sebastián. 2010. “¿Jugadores activos o apéndices del Ejecutivo? Una evaluación del papel de los legisladores latinoamericanos en la toma de decisiones". Política y Gobierno 17 (1): 3-24.

Samuels, David. 2000. "Explaining Legislative Turnover in Brazil". Legislative Studies Quarterly 25 (3): 481-497.

Siavelis, Peter. 2000. The President and Congress in Postauthoritarian Chile: Institutional Constraints to Democratic Consolidation. Pennsylvania: The Pennsylvania State University Press.

Siavelis, Peter. 2002. "Exaggerated Presidentialism and Moderate Presidents: Executive-Legislative Relations in Chile". En Legislative Politics in Latin America, editado por S. Morgenstern y B. Nacif. Cambridge: Cambridge University Press.

Siavelis, Peter. 2005. "La lógica oculta de la selección de candidatos en las elecciones parlamentarias chilenas". Estudios Públicos 98: 198-225.

Shugart, Matthew y John Carey. 1992. Presidents and Assemblies: Constitutional Design and Electoral Dynamics. Cambridge: Cambridge University Press.

Toro, Sergio. 2007. "Conducta legislativa ante las iniciativas del Ejecutivo: Unidad de los bloques políticos en Chile". Revista de Ciencia Política 27 (2): 23-41.

Giancarlo Visconti es Cientista Político de la Pontificia Universidad Católica de Chile. Ha trabajado en el proyecto Auditoría de la Democracia (PNUD) y en el Proyecto de Opinión Pública de América Latina (LAPOP Chile). Sus áreas de interés son las relaciones ejecutivo-legislativo y los estudios legislativos.

E-mail: gviscont@uc.cl 
